Available online on 15.11.2019 at http://ujpr.org
Universal Journal of Pharmaceutical Research
An International Peer Reviewed Journal
Open access to Pharmaceutical research

\title{
THE EFFECT OF NANOSILVER AND CHLORHEXIDINE MOUTHWASH ON ANAEROBIC PERIODONTAL PATHOGENS COUNTS Amani Abdulhakeem Al-Sharani ${ }^{1}$ (D) Waddah Al-Hajji ${ }^{1}$, Hassan A. Al-Shamahy ${ }^{2 *}$ (D) Bushra Mohammed Jaadan ${ }^{3}$ (D) \\ ${ }^{1}$ Oral Medicine and Periodontology Department, College of Dentistry, University of Sciences and Technology, Yemen. ${ }^{2}$ Medical Microbiology and Clinical Immunology Department, Faculty of Medicine and Health Sciences, Sana'a University, Republic of Yemen. \\ ${ }^{3}$ Medicinal Chemistry, Faculty of Pharmacy, Sana'a University, Republic of Yemen.
}

\section{ABSTRACT}

Objective: The necessitate for frequent application of Chlorhexidine (CHX), and other side effects has encouraged the search for option that are more suitable for patients as nanosilver mouthwash (NS). So the aim of this study was to determine the effects of a mouthwash made with nanosilver on dental plaque microbial counts and compare it with commercially available Chlorhexidine. Methods: Sixty two plaque induced gingivitis patients were allocated into two groups and asked to rinse with $10 \mathrm{ml}$ of NS and CHX, immediately after brushing, for $1 \mathrm{~min}$, in the morning and evening. Sub gingival plaque microbial counts were taken at baseline, two weeks, and finally at four weeks for each patient. Subsequently, the samples were collected, transferred and cultured in blood agar in anaerobic media. The colonies were counted and expressed as CFUs. The statistical analysis between CFUs variables within groups was calculated and the variation significance was calculated by performed $\mathrm{t}$-test.

Results: It is very obvious that the values of CFU decreased significantly $(p<0.001)$ as the time of use nanosilver until reaching the highest value when the time of use was 4 weeks [70.3 \pm 47 to $32.4 \pm 24.6$ ( 2 weeks), and $14.2 \pm 9.9$ (4 weeks) with inhibition of growth rate after 2 weeks was $46 \%$ and after 4 weeks was $79.7 \%$. The effect of commercially available CHX mouthwash was approximately similar to the effect of NS mouthwash used.

Conclusion: In conclusion, both Group I and Group II showed similar effect on inhibition anaerobic periodontal pathogens counts and gingival health. There was significant inhibitory effect on microbial counts where NS mouth-wash had shown better results than $C H X$, but there was no significant difference between the nanosilver mouth wash and the Chlorhexidine mouthwash.

Keywords: Anaerobic periodontal pathogens, Chlorhexidine mouthwash, CFU, nanosilver mouthwash.

Article Info: Received 1 September 2019; Revised 2 November; Accepted 8 November, Available online 15 November 2019

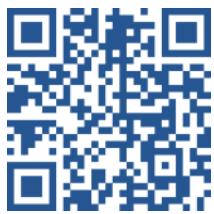

Cite this article-

Al-Sharani AA, Al-Hajj W, Al-Shamahy HA, Jaadan BM.The effect of nanosilver and chlorhexidine mouthwash on anaerobic periodontal pathogens counts. Universal Journal of Pharmaceutical Research 2019; 4(5):1-6.

DOI:https://doi.org/10.22270/ujpr.v4i5.309

Address for Correspondence:

Prof. Hassan A. Al-Shamahy, Faculty of Medicine and Heath Sciences Sana'a University, Yemen.Tel: +967-1-239551, E-mail: shmahe@yemen.net.ye

\section{INTRODUCTION}

Over a period of time it has been observed that the cost for the preservative dentistry is similar to and possibly less than the cost of introduction and replacing dental restorations. The early intervention concept is interesting as it may be easier to affect the cariesassociated bacteria before their permanent colonization compared with later in life when the resident oral flora is firmly established ${ }^{1}$. Dental caries in adults and children has a multifactorial etiology; therefore preventive measures usually involve a combination of dietary counseling, oral hygiene, and fluoride application ${ }^{1}$.None of these interventions specifically target anaerobic periodontal pathogens the chief pathogens responsible for caries. An antibacterial agent that is effective and also acceptable to adults and children will be a useful supplement to current techniques for the prevention of caries ${ }^{2}$.

Chlorhexidineis the antimicrobial agent most familiar to dental professionals for prevention of dental caries in adults and children ${ }^{3}$. The necessitate for frequent application of Chlorhexidine, and other side effects such as unlikable taste and staining, has encouraged the search for option that are more suitable for patients as nanosilver mouthwash. Silver $(\mathrm{Ag})$ nanomaterials (nanosilver) are widely utilized today for their antibacterial activity. In medical care nanosilver has been used, for example, as an antibacterial agent in wound dressings ${ }^{4}$, such as bandages to protect patients with severe burns against infections. It has also been 
used in catheters to prevent the formation of infectious biofilm ${ }^{5}$. It can be anticipated that, with prices of medical applications of nanosilver decreasing, their use will increase. Nanosilver has also been used in consumer products such as sports textiles, other textiles, washing powder and deodorants, where nanosilver should reduce undesired odours. The last 10 years review papers suggest that at the current level of exposure nanosilver may not be hazardous to humans and may result in low internal exposure ${ }^{6,7,8}$. In this circumstance, a study was undertaken to ascertain the effects of a mouthwash prepared with nanosilver on the dental plaque, gingival inflammation, and microbial counts in adults, and to compare the effect of it with commercially available Chlorhexidine mouthwash.

\section{MATERIALS AND METHODS}

This study was conducted at the Department of Oral Medicine and Periodontology, College of Dentistry, University of Sciences and Technology, in collaboration with the Department of Microbiology, Faculty of Medicine and Health Sciences University of Sciences and Technology. Approval from the University of Sciences and Technology Ethics Committee was obtained before initiating the study (MECA NO.: 2016/22). All patients signed an informed consent form.

Study Design: This study was a triple-blinded randomized controlled comparative trial of four weeks duration, conducted in the Dental Polyclinics of the Dental College at University of Science and Technology (UST), Sana'a, Yemen.

Study Population: The sample of the present study consisted of patients with average age of 23 years referred for treatment to the Dental Polyclinics of the Dental College at UST. The subjects were enrolled between January and November 2017. The inclusion criteria of this study comprised good general health, availability for the 4 weeks duration of the study, patients who have evidence of plaque-induced gingivitis without periodontitis, and a minimum of 20 natural teeth, excluded third molars. Subjects were excluded from the study if they had any of the following conditions: orthodontic bands; partial removable dentures; pregnant or breast feeding women; subjects who had systemic disorders and/or undertake medication which might influence the periodontal; individuals with history of allergic to oral consumer products; smoking; patients who received periodontal treatment or antibiotic therapy any time during the one month prior to entry into the study; subjects who had tumor(s) or significant pathology in the soft or hard tissues of the oral cavity; five or more carious lesions needful immediate care; subjects received a dental prophylaxis in the past two weeks prior to the baseline examination. After a screening examination that comprised a full medical and dental history and intraoral examination, the final sample size in the study consisted of 62 patients' with plaqueinduced gingivitis (28 males and 34 females) according to the inclusion/exclusion criteria. The subjects were then randomly divided into two groups as shown in Figure 1: The control group that consisted of 34 patients who rinsed with $0.12 \%$ chlorhexidine mouthwash (Shiba Pharma co., Yemen), 10ml for one minute twice daily. The experimental group included 34 patients who rinsed with a nanosilver mouthwash (Nanogist co., Korea), $10 \mathrm{ml}$ for one minute twice daily.

Experimental Design: All patients received a complete dental prophylaxis to remove all plaque, calculus and extrinsic stain before entering the study ${ }^{9}$. The participants were motivated on regular intervals by personal and phone contact, to use tooth brush and mouthwash on regular basis. The patients were instructed to use soft tooth brush, brush only with similar toothpaste ${ }^{9}$ (Colgate ${ }^{\circledR}$ Cavity Protection fluoride toothpaste) and to brush their teeth twice daily, once in the morning after breakfast and once in the evening before bedtime. They were instructed to brush a minimum of 3 minutes to ensure thorough brushing. They were instructed to rinse their mouth with mouth wash at least half an hour after tooth brushing and instructed not to take any liquid or food for at least 30 minutes after using mouth wash to avoid reduction the substantively of mouth wash, thus decreasing the efficacy of the mouth wash and to diminish the side effects of CHX like staining and bad taste ${ }^{10}$. All mouth washes were wrapped by an assistant in opaque vials containing the codes $\mathrm{A}$ and $\mathrm{B}$. The assistant added a new patient to a list of randomly assigned letters (A and B), and the patient was given the medication assigned that letter. Thus, this way the triple blinding of the examiner, the statistician and the subjects was achieved. The calibration performed for this step showed highly intra-examiner agreement (Kappa $=0.90$ ) was achieved.

Sub-gingival Plaque Sampling: Plaque sample was taken at baseline, two weeks, and finally at four weeks. The quadrant teeth were primarily isolated using cotton wool rolls, the lingual surface of the teeth was dried with a gentle stream of air and a saliva ejector was used to maintain sampled area dry. The plaque samples were obtained by insertion of standardized \#40 a sterile disposable paper point into the deepest part of periodontal sulcus from lingual surface of the tooth number 36 and 16 (the lower left 1st molar and upper right 1st molar) and left in situ for few seconds, pooled separately, placed in $5 \mathrm{ml}$ tryptone soya broth sterile tubes and stored in a refrigerator at $+4^{\circ}$ until analysis.

Sample Analysis: Plaque samples were put in tube contains $1 \mathrm{ml}$ normal saline $(0.9 \% \mathrm{Nacl})$ then vortexed for 30 seconds; next ten folds dilution was done to have $10^{-2}$ (100 fold) dilution to permit the colonies forming units countable. By $50 \mu \mathrm{L}$ micropipette, the serial dilutions were cultured on blood agar media. The plates were incubated at $37^{\circ} \mathrm{C}$ for 48 hours. The anaerobic conditions were obtained by using simple anaerobic jar in conjunction with a standardized anaerobic procedure and using of anaerobic gas pack system. The number of bacteria in a culture was estimated by direct counting of the organisms, all colonies with different morphologies, colors, sizes and hemolytic reactions were selected and results were expressed as a colony forming units per sample (CFU/ sample). CFU on each plate were counted manually. 


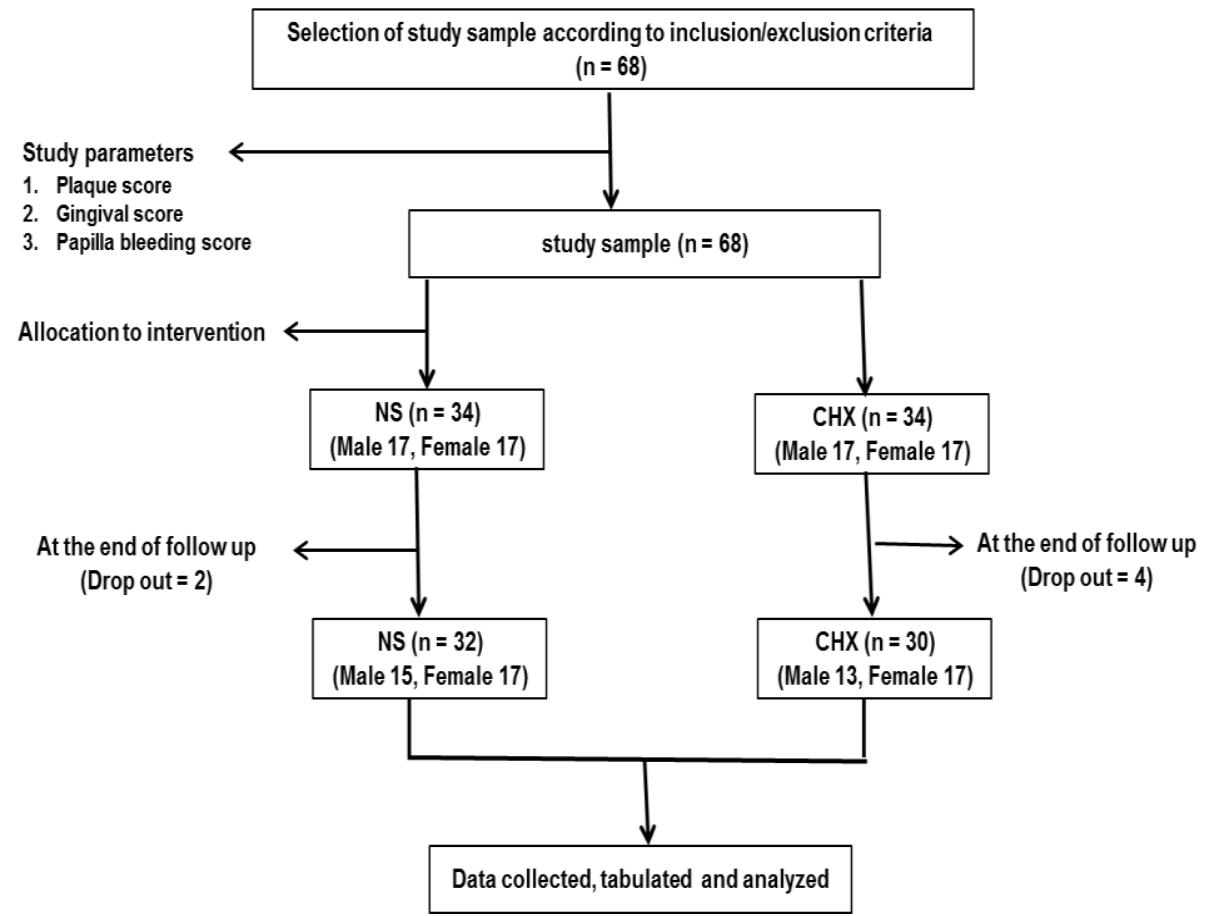

Figure 1: Experimental Design.

Statistical Analysis: The analysis of the data was performed using SPSS 21.0 for Windows (SPSS Inc., Chicago, IL, USA). The Mann-Whitney U-test was used to determine statistical significance of mean values between groups (intergroup analysis). The bacterial count (CFUs) within the groups was evaluated using the Wilcoxon signed rank test (intergroup analysis). The significance level was set at $p<0.05$.

\section{RESULTS}

At the onset of the study, there were 68 participants. Six participants dropped out, 2 from NS group, and 4 from CHX group, thus at the end of the study, 62 participants were present $(\mathrm{CHX}=30$, and $\mathrm{NS}=32)$.

\begin{tabular}{|c|c|c|c|}
\hline \multirow{3}{*}{$\begin{array}{l}\text { CFU } \\
\text { Values }\end{array}$} & \multirow{2}{*}{\multicolumn{3}{|c|}{ Time of uses (week) }} \\
\hline & & & \\
\hline & $\begin{array}{c}\text { Zero } \\
\text { A }\end{array}$ & $\begin{array}{c}2 \text { weeks } \\
\text { B }\end{array}$ & $\begin{array}{c}4 \text { weeks } \\
\text { C }\end{array}$ \\
\hline Mean & 70.3 & 32.4 & 14.2 \\
\hline Variance & 2299 & 606 & 98 \\
\hline $\begin{array}{l}\text { Standard } \\
\text { division }\end{array}$ & 47 & 24.6 & 9.9 \\
\hline $\begin{array}{l}\text { Standard } \\
\text { error }\end{array}$ & 8.6 & 4.4 & 1.7 \\
\hline Min & 8 & 5 & 0 \\
\hline Max & 216 & 115 & 40 \\
\hline Median & 76 & 30 & 12 \\
\hline Mode & 77 & 38 & 7 \\
\hline Sum & 2181 & 1005 & 442 \\
\hline student test & 8.1 & 7.3 & 8.1 \\
\hline$P$ value & $<0.001$ & $<0.001$ & $<0.001$ \\
\hline $\begin{array}{l}\text { Inhibition } \\
\text { growth rate }\end{array}$ & Ref & $46 \%$ & $79.7 \%$ \\
\hline
\end{tabular}

Dropping out was due to failure in following the study protocol. Intergroup comparison by Mann- Whitney Utest showed no statistically significant differences between the groups at baseline for all studied parameters. Table 1shows the antimicrobial effect of nanosilver mouth wash on the CFU of anaerobic plaque pathogens at different time of use. It is very obvious that the values of CFU decreased significantly $(p<0.001)$ as the time of use nanosilver mouth wash until reaching the highest value when the time of use was 4 weeks. There was increase in the inhibition of growth with time of use in which the inhibition rates for 2 weeks used and for 4 weeks used were $46 \%$ and $79.7 \%$ respectively.

Table 2: The antimicrobial effect of chlorohexidene mouth wash on the CFU of anaerobic plaque pathogens at different time of use.

\begin{tabular}{lccc}
\hline \multirow{2}{*}{ CFU Values } & \multicolumn{3}{c}{ Time of uses (week) } \\
\cline { 2 - 4 } & Zero & 2 weeks & 4 weeks \\
\hline Mean & 63.3 & 30.9 & 14.5 \\
Variance & 3063 & 70.4 & 123 \\
Standard & 55.3 & 26.5 & 11.1 \\
division & & & \\
Standard error & 9.9 & 4.7 & 1.9 \\
Min & 10 & 5 & 1 \\
Max & 300 & 138 & 43 \\
Median & 48 & 22 & 11 \\
Mode & 40 & 20 & 7 \\
Sum & 1964 & 959 & 451 \\
Significant & 6.3 & 6.4 & 7.2 \\
variation & & & \\
(student test) & & & \\
P value & $<0.001$ & $<0.001$ & $<0.001$ \\
Inhibition & Ref & $51.2 \%$ & $77 \%$ \\
growth rate & & & \\
\hline
\end{tabular}

Also, there was decrease of Mean $\pm \mathrm{SD}$ of CFU as we proceed from A: zero time of nanosilver mouth wash use; B: 2 weeks, and C: 4 weeks $[70.3 \pm 47$ to $32.4 \pm 24.6$ (2 weeks), and $14.2 \pm 9.9$ (4 weeks). In intergroup comparison CFU of the bacteria at each period of use nanosilver mouth wash was compared to the CFU at all 
the periods of use; there was a high significant statistical difference between the zero time (had no use) and the 4 weeks $(p<0.001)$ (Table 1). Table 2 shows the antimicrobial effect of chlorohexidene mouth wash on the CFU of anaerobic plaque pathogens at different time of use.

Table 3: The significance of the antimicrobial effect of nanosilver mouth wash on the mean \pm SD CFU of anaerobic plaque pathogens at different period of use.

\begin{tabular}{|c|c|c|}
\hline \multirow{2}{*}{$\begin{array}{l}\text { Time of } \\
\text { use } \\
\text { (week) }\end{array}$} & \multicolumn{2}{|c|}{$\begin{array}{c}\text { CFU of anaerobic plaque } \\
\text { pathogens }\end{array}$} \\
\hline & Mean \pm SD & P value \\
\hline $\begin{array}{l}\text { Zero } \\
\text { (baseline) }\end{array}$ & $70.3 \pm 47$ & Refe \\
\hline & $32.4 \pm 24.6$ & $P=0$ \\
\hline 4 weeks & $14.2 \pm 9.9$ & $\mathrm{P}<0.0001$ \\
\hline
\end{tabular}

It is very obvious that the values of CFU decreased significantly $(p<0.001)$ as the time of use chlorohexidene mouth wash until reaching the highest value when the time of use was 4 weeks.

Table 4: The significance of the antimicrobial effect of chlorohexidene mouth wash on the mean \pm SD CFU of anaerobic plaque pathogens at different period of use

Time of use CFU anaerobic plaque

(week) pathogens bacteria

\begin{tabular}{lcc}
\cline { 2 - 3 } & Mean \pm SD & P value \\
\hline Zero (baseline) & $63.3 \pm 55.3$ & Reference \\
Ref & & \\
2 weeks & $30.6 \pm 26.5$ & 0.0043 \\
4 weeks & $14.5 \pm 11.1$ & $<0.0001$ \\
\hline
\end{tabular}

There was increase in the inhibition of growth with time of use in which the inhibition rates for 2 weeks use and for 4 weeks use were $51.2 \%$ and $77 \%$ respectively. As well, there was decrease of mean $\pm \mathrm{SD}$ of $\mathrm{CFU}$ as we proceed from A: zero time of chlorohexidene mouth wash use; B: 2 weeks, and C: 4 weeks $[63.3 \pm 55.3$ to $30.9 \pm 14.5$ (2 weeks), and $14.5 \pm 11.1$ (4 weeks).

Table 5: Comparison of antimicrobial effect of nanosilver mouthwash with of chlorohexidene mouth wash on CFU of anaerobic plaque pathogens.

\begin{tabular}{lccc}
\hline $\begin{array}{l}\text { Time of } \\
\text { use (week) }\end{array}$ & $\begin{array}{c}\text { Nanosilver } \\
\text { mouth- } \\
\text { wash } \\
\text { Mean } \pm \text { SD }\end{array}$ & $\begin{array}{c}\text { chlorohexidene } \\
\text { mouth wash } \\
\text { Mean } \pm \text { SD }\end{array}$ & $\begin{array}{c}\text { P } \\
\text { value }\end{array}$ \\
\hline $\begin{array}{l}\text { Zero } \\
\text { (baseline) }\end{array}$ & $70.3 \pm 47$ & $63.3 \pm 55.3$ & NS \\
2 weeks & $32.4 \pm 24.6$ & $30.6 \pm 26.5$ & NS \\
4 weeks & $14.2 \pm 9.9$ & $14.5 \pm 11.1^{*}$ & NS \\
\hline \multicolumn{4}{c}{ NS $>0.05$}
\end{tabular}

Table 3 shows the significance of the antimicrobial effect of nanosilver mouth wash on the mean \pm SD CFU of anaerobic plaque pathogens at different period of use.It is very obvious that the mean $\pm \mathrm{SD}$ of $\mathrm{CFU}$ decreased significantly as the time of use nanosilver mouth wash in which the mean $\pm S D$ at zero time $70.3 \pm 47$, decreased to $32.4 \pm 24.6$ after 2 weeks of use $(P<0.0001)$, until reaching $14.2 \pm 9.9$ when the time of use was 4 weeks (0.0002). Table 4 shows the significance of the antimicrobial effect of chlorohexidene mouth wash on the mean \pm SD CFU of anaerobic plaque pathogens at different period of use. It is very obvious that the mean $\pm \mathrm{SD}$ of CFU decreased significantly as the time of use chlorohexidene mouth wash in which the mean \pm SD at zero time $63.3 \pm 55.3$ decreased to $30.6 \pm 26.5$ after 2 weeks of use $(P<0.0043)$, until reaching $14.5 \pm 11.1$ when the time of use was 4 weeks $(<0.0001)$. Table 5 shows the mean \pm SD values of bacterial count of both NS and CHX groups. There is no statistically significant difference between NS and CHX groups for bacterial counts at 2 and 4 weeks follow up. The bacterial counts was lower in the NS group than that in $\mathrm{CHX}$ group, but there is no significant difference between them at the three experimental time points $(\mathrm{p}>0.05)$.

\section{DISCUSSION}

Dental plaque has long been considered to be the main etiological agent in gingivitis and periodontal disease. Therefore, suitable plaque control is very vital to prevent the incidence of the abovementioned disease ${ }^{11}$. The plaque control can be accomplished by mechanical, chemical, or by a combination of the both. Mouthwash which is a chemical plaque control should be used along with mechanical hygiene ${ }^{12,13}$. It has been recommended being a regular adjunct along with mechanical therapy to maintain oral health ${ }^{14}$. Among the available mouthwashes, $\mathrm{CHX}$ is considered to be the gold standard and is part of the periodontal treatment regimen ${ }^{10}$. However, CHX is known to have various side effects ranging from minor effects such as alteration in patient taste sensation and staining of teeth to certain less common effects such as mucosal erosion or parotid swelling ${ }^{\mathbf{1 0} 15,16}$. Considering the adverse effects of the use of CHX, its use for long-term therapy has been limited or not actively recommended ${ }^{16}$. Several mouthwashes without the similar negative effects as CHX have been tried for long-term therapy, but none has been successful in providing similar antiplaque and antigingivitis effect as $\mathrm{CHX}^{10,15,16}$. NS mouthwash has gained attention for their antimicrobial properties ${ }^{17}$. This is attributed to that NS products has small size properties (nanoparticles), which they have potential to penetrate the microorganisms and destroy them. Thus, the present study was conducted to compare the effects of NS and CHX on treatment of patients with plaque-induced gingivitis using bacterial counts. Various methods have been used to investigate the equivalence of the mouthwash in killing the bacteria, including polymerase chain reaction (PCR), culture procedures, minimum inhibitory concentration (MIC) and minimum bactericidal concentration $(\mathrm{MBC})^{18-20}$

In the current study, It was very obvious that the values of CFU decreased significantly $(p<0.001)$ as the time of use nanosilver mouth wash until reaching the highest value when the time of use was 4 weeks (table 1). The antibacterial effects of NS in the current study is in agreement with a study conducted by Halkai et al. ${ }^{21}$ who found that NS revealed effective antibacterial ability against $P$. gingivalis, also with numerous studies that demonstrated; reduction of 
microbial infections after use of $\mathrm{NS}^{22-25}$. In the current study; also the bacterial counts was lower in the NS group than in CHX group, but there was no significant difference between them at the three experimental time points $(\mathrm{p}>0.05)$. (Table5). In contrast to the current study Esfahanian et al. ${ }^{26}$ showed that CHX mouthwash had a significant statistical superiority in comparison with the NS mouthwash in antimicrobial activity. Additionally, Ahrari et al., ${ }^{20}$ also found that the NS produced antibacterial effects significantly lower than that of the $0.2 \% \mathrm{CHX}$ mouthwash. The difference between the current study result and previous studies could be due to that they tested the different effect in vitro conditions. However, the current study results is different from positive result for NS over CHX that reported by Kariminik et al., ${ }^{27}$ which showed that NS mouthwash was more effective than $\mathrm{CHX}$ in killing bacteria. These differences from the present study might be attributed to that the bacterial samples were taken from saliva, not dental plaque as in the current study. Basins et al., ${ }^{28}$ showed that NS had the strongest antibacterial activity of the NPs tested, with bacterial growth lower than that in CHX. Mozayeni et al., ${ }^{29}$ indicated that NS gel were significantly had less effect than that of $\mathrm{CHX}$ gel against $C$. albicans.

As a final point, there are limitations in the current study that should be considered. The number of plaqueinduced gingivitis persons studied was lower; further study with a larger sample size number should be performed to confirm the results. Lastly, the follow-up period was only 4 weeks; further study with a long follow-up period should be take into account.

\section{CONCLUSION}

Within the limitations of the present study, it can be concluded that the NS and CHX mouthwashes reduced bacterial counts in patients with plaque-induced gingivitis roughly in equal effect. This study confirmed the anti-microbial activities ofNS. Also, NS is considered as an antimicrobial alternative to the CHX as mouthwash suitable for plaque control.

\section{CONFLICTS OF INTEREST}

There are no any conflicts of interest.

\section{ETHICAL APPROVAL}

The study protocol was approved by the Ethical Committee of the Faculty of Medicine at UST, Yemen (MECA NO.: 2016/22).

\section{AUTHOR'S CONTRIBUTION}

The manuscript was carried out, written, and approved in collaboration with all authors.

\section{ACKNOWLEDGEMENT}

The authors would like to thank the managements of the Collage of Dentistry and hospital of University of Science and Technology for their assistance and supports.

\section{REFERENCES}

1. Aspalli S, Shetty VS, Devarathnamma M, Nagappa G, Archana D, Parab P. Evaluation of antiplaque and antigingivitis effect of herbal mouthwash in treatment of plaque induced gingivitis: A randomized, clinical trial. J Indian Soc Periodontol 2014; 18(1):48.

https://doi.org/10.4103/0972-124X.128208

2. Priya BM, Galgali SR. Comparison of amine fluoride and chlorhexidine mouth rinses in the control of plaque and gingivitis-A randomized controlled clinical trial. Indian $\mathbf{J}$ Dent Res 2015; 26(1):57. https://doi.org/10.4103/0970-9290.156809

3. Mahajan R, Khinda PK, Gill AS, Kaur J, Saravanan S, Sahewal A, et al. Comparison of efficacy of $0.2 \%$ chlorhexidine gluconate and herbal mouth rinses on dental plaque:an in vitro comparative Study. Eur J Med Plants 2016; 13(2):1.PMID: 26464549

4. Wijnhoven SWP, Peijnenburg WJGM, Herbert CA, Hagens WI, Oomen AG, Heugens EHW, et al. Nanosilver-a review of available data and knowledge gaps in human and environmental risk assessment. Nanotoxicol 2009; 3, 10938. https://doi.org/10.1080/17435390902725914

5. Silver S, Phung 1T, Silver G. Silver as biocides in burn and wound dressings and bacterial resistance to silver compounds. J Ind Microbiol Biotechnol 2006; 33(7):62734.https://doi.org/10.1007/s10295-006-0139-7

6. Nowack B, Krug HF, Height M. 120 Years of Nanosilver History: Implications for Policy Makers. Environ Sci Technol 2011; 45 (4): 1177-1183. https://doi.org/10.1021/es103316q

7. Ahamed M, Alsalhi MS, Siddiqui MK. Silver nanoparticle applications and human health. Clin Chim Acta 2010; 411(23-24):1841-8. https://doi.org/10.1016/j.cca.2010.08.016

8. Johnston HJ, Hutchison G, Christensen FM. A review of the in vivo and in vitro toxicity of silver and gold particulates: particle attributes and biological mechanisms responsible for the observed toxicity. Crit Rev Toxicol 2010; 40(4):328-46. https://doi.org/10.3109/10408440903453074

9. Chandrasekaran K. Evaluation of a herbal mouthwash (BefreshTM) Vs. chlorhexidine mouthwash (Clohex Plus): a prospective clinical and microbiological study. EC Microbiology 2017; 7:209-18. https://doi.org/10.7759/cureus.4968

10. Balagopal S, Arjunkumar R. Chlorhexidine: the gold standard antiplaque agent. J Pharm Sci Res 2013; 5(12):270-4. https://doi.org/10.1111/j.1600-0757.1997.tb00105.x

11. Farah CS, Mcintosh L, Mccullough MJ. Mouthwashes. Aust Prescr 2009; 32:162-4. https://doi.org/10.18773/austprescr.2009.080

12. Esfahanian V, Mohamadi F, Amini S. An in vitro comparison of antimicrobial effect of nanosil and chlorhexidine mouthrinses. J Islamic Dental Assoc Iran 2012; 24(3):238-43.https://doi.org/10.1038/sj.bdj.4809913

13. Chatterjee A, Debnath K, Rao NKH. A comparative evaluation of the efficacy of curcumin and chlorhexidine mouthrinses on clinical inflammatory parameters of gingivitis: A double-blinded randomized controlled clinical study. J Indian Soc Periodontol 2017; 21(2): 132-137. https://doi.org/10.4103/jisp.jisp_136_17

14. Arora V, Tangade P, Ravishankar TL, Tirth A, Pal S, Tandon V, et al. Efficacy of dental floss and chlorhexidine mouth rinse as an adjunct to toothbrushing in removing plaque and gingival inflammation- A three way cross over trial. J Clin Diagn Res 2014; 8:ZC01-4 https://doi.org/10.7860/JCDR/2014/8807.4943

15. Graziani F, Gabriele M, D’Aiuto F, Suvan J, Tonelli M, Cei S. Dental plaque, gingival inflammation and toothdiscolouration with different commercial formulations of $0.2 \%$ chlorhexidine rinse: a double-blind randomized controlled clinical trial. Oral Health Prev Dent 2015; 13: 101-111. https://doi.org/10.3290/j.ohpd.a32827

16. Charles $\mathrm{CH}$, Mostler KM, Bartels LL, Mankodi SM. Comparative antiplaque and antigingivitis effectiveness of a 
chlorhexidine and an essential oil mouthrinse: 6-month clinical trial. J Clin Periodontol 2004; 31:878-84. https://doi.org/10.1111/j.1600-051X.2004.00578.x

17. Osso D, Kanani N. Antiseptic mouth rinses: An update on comparative effectiveness, risks and recommendations. J Dent Hyg 2013; 87:10-8.

18. Lau L, Sanz M, Herrera D, Morillo JM, Martín C, Silva A. Quantitative real time polymerase chain reaction versus culture: a comparison between two methods for the detection and quantification of Actinobacillus actinomycetemcomitans, Porphyromonas gingivalis and Tannerella for sythensis in subgingival plaque samples. J Clin Periodontol 2004; 31(12):1061-9. https://doi.org/10.1902/jop.2007.060078

19. Garibyan L, Avashia N. Research techniques made simple: polymerase chain reaction (PCR). J Inves Dermatol 2013; 133(3):e6. https://doi.org/10.1038/jid.2013.1

20. Ahrari F, Eslami N, Rajabi O, Ghazvini K, Barati S. The antimicrobial sensitivity of Streptococcus mutans and Streptococcus sangius to colloidal solutions of different nanoparticles applied as mouthwashes. Den Res J 2015; 12(1):44.PMID: 25709674

21. Halkai KR, Mudda JA, Shivanna V, Rathod V, Halkai RS. Biosynthesis, Characterization and antibacterial efficacy of silver nanoparticles derived from endophytic fungi against P. gingivalis. J Clin Diagnostic Res 2017; 11(9):ZC92. https://doi.org/10.7860/JCDR/2017/29434.10681

22. Shawky HA, Soha M, Gihan A. Evaluation of clinical and antimicrobial efficacy of silver nanoparticles and tetracycline films in the treatment of periodontal pockets. IOSR J Dent Med Sci 2015; 14:113-23. https://doi.org/10.9790/0853-1471113123

23. Lu Z, Rong K, Li J, Yang H, Chen R. Size-dependent antibacterial activities of silver nanoparticles against oral anaerobic pathogenic bacteria. J Mater Sci: Mater Med 2013; 24(6):1465-71.

https://doi.org/10.1007/s10856-013-4894-5

24. Freire PL, Albuquerque AJ, Sampaio FC, Galembeck A, Flores MA, Stamford T, et al. AgNPs: The New Allies Against S. Mutans Biofilm-A Pilot Clinical Trial and Microbiological Assay. Braz Dent J 2017; 28(4):417-22. https://doi.org/10.1590/0103-6440201600994

25. Sadeghi R, Owlia P, Yaraee R, Sharif F, Taleghani F. An in vitroassessment of antimicrobial and cytotoxic effects of nanosilver. J Med Bacteriol 2015; 1(3-4):44-52.

26. Rosin M, Welk A, Kocher T, Majic-Todt A, Kramer A, Pitten FA. The effect of a polyhexamethylene biguanide mouthrinse compared to an essential oil rinse and achlorhexidine rinse on bacterial counts and 4-day plaque regrowth. J Clin Periodont 2002; 98: 392-399. https://doi.org/10.1034/j.1600-051X.2002.290503.x

27. Kariminik A, Motaghi M-M. Evaluation of Antimicrobial susceptibility pattern of Streptococcus mutans isolated from dental plaques to chlorhexidine, nanosil and common antibiotics. Int J Life Sci 2015; 9(2):18-21. https://doi.org/10.3126/ijls.v9i2.12040

28. Besinis A, De Peralta T, Handy RD. The antibacterial effects of silver, titanium dioxide and silica dioxide nanoparticles compared to the dental disinfectant chlorhexidine on Streptococcus mutans using a suite of bioassays. Nanotoxicol 2014; 8(1):1-16. https://doi.org/10.3109/17435390.2012.742935

29. Mozayeni MA, Hadian A, Bakhshaei P, Dianat O. Comparison of antifungal activity of $2 \%$ chlorhexidine, calcium hydroxide, and nanosilver gels against Candida albicans. J Dent (Tehran) 2015; 12(2):109. https://doi.org/10.1088/0957-4484/16/10/059 